\title{
O Ensino de Climatologia Geográfica: uma abordagem de intervenção sobre os conceitos básicos de Clima e Tempo
}

Teaching Geographic Climatology: an approach to the basics of Climate and Weather

DANTAS ${ }^{1}$, S. P.

sulivandantas@yahoo.com.br

\section{Resumo}

A climatologia geográfica como conteúdo da disciplina de Geografia traz consigo diversas situações que podem ser abordadas dentro da sala de aula, assim como do ambiente escolar. Entretanto, entre as várias dificuldades encontradas pelo docente de Geografia, os desafios são: a abordagem dos conteúdos da climatologia de acordo com as suas mais recentes concepções, diante dos recursos (in) disponíveis na maioria das escolas da rede pública de ensino fundamental, e o esforço intelectual a ser feito para sua conotação geográfica já. Através da pesquisa qualitativa de Estudo de Caso nos sextos anos do Ensino Fundamental da Escola pública do município de Fortaleza/CE foi possível mostrar se há de fato a utilização de recursos didáticos ou não na sala de aula, onde tivemos como resultado dificuldades quanto ao ensino de Geografia e aos conteúdos de Climatologia. Assim foram listados alguns conteúdos de clima e a partir de entrevistas com os alunos do ano supracitado foi possível identificar que eles têm maior dificuldade em definir e diferenciar Tempo e Clima, expressando vários motivos.

Palavras-chave: Ensino de Geografia, Clima, Conceitos.

\begin{abstract}
The geographical climatology and geography discipline content brings different situations that can be addressed within the classroom, and the school environment. However, among the various difficulties encountered by the teacher of Geography, the challenges are: addressing climatology content according to their latest designs, before the resources (in) available in most public schools of primary education, and the intellectual effort to be made to its geographical connotation already. Through qualitative research case study in the 6th year of elementary school public school in the city of Fortaleza / $\mathrm{CE}$ was possible to show whether there is in fact the use of educational resources or not in the classroom, where we had as a result of difficulties for teaching Geography and Climatology content. So they were listed some weather content and from interviews with students of the aforementioned year was possible to identify that they are more difficult to define and differentiate Weather and Climate, expressing various reasons.
\end{abstract}

Keywords: Geography Teaching, Climate, Concepts

\section{INTRODUÇÃO}

A necessidade de conhecer a atual organização do espaço geográfico e entendê-lo para ensinar faz do estudo da Geografia um elemento imprescindível ao ensino formal, visto seu poder de fomentar um ideário que internaliza as dimensões da teia da produção do espaço.

A Geografia escolar do Ensino Fundamental é a fase escolar que permite ao aluno compreender a espacialidade dos fenômenos em seus múltiplos recortes (local, regional, nacional e global). Tudo isso lança desafios ao ensino desta ciência, que assume novos papéis no atual contexto social do país. Criar, dessa forma, contextos educacionais que possibilitem condições de ensinar aos alunos, demanda responsabilidade, dedicação, comprometimento e reorganização constante do trabalho escolar. 
Nesse contexto e considerando a importância de proporcionar aos alunos uma reflexão sobre seu mundo, faz-se necessário destacar as semelhanças e as diferenças entre os lugares e esclarecer como as relações sociedade-natureza se estabelecem nos diferentes planos espaço-temporal.

Sob esta perspectiva, conhecer e entender a dinâmica do funcionamento da natureza e a interação entre seus elementos compõem os objetivos da Geografia, cuja interface com a Climatologia evidencia-se pela importância de sua variação no espaço geográfico e no tempo.

No ensino de Geografia, o conteúdo de climatologia precisa não só da utilização de metodologias, mas da preparação adequada do professor. Pensando na própria eficácia da prática educativa valorativa ao professor e ao educando, necessita-se de um processo de ensinoaprendizagem que traga de fato correlações da realidade com o saber científico.

Vale mencionar que os Parâmetros Curriculares Nacionais (PCNs), documentos formalizados pelo Ministério da Educação (MEC), institucionalizam a discussão dos mecanismos climáticos como, por exemplo, a dinâmica das massas de ar; as variações diárias de tipos de tempos atmosféricos; a ocorrência e distribuição dos tipos de clima sobre a superfície terrestre e do lugar onde se vive e a relação dos tipos de clima e as atividades humanas. Pois quando os alunos se familiarizam com as leis que regulam o tempo atmosférico, as estações do ano e os climas, elas podem compreender suas relações com as diversas paisagens vegetais, os tipos de solo, a organização das bacias hidrográficas e o regime dos rios.

Como efeito, encontram-se desafios no ensino de climatologia, desde sua abordagem dentro do ambiente escolar até as dificuldades encontradas pelos professores em ministrarem muito dos conteúdos referentes a este tema e também, da dificuldade por parte dos alunos para perceber o clima como integrante da paisagem.

Nesta pesquisa buscou-se levantar os conteúdos de climatologia que os alunos têm mais dificuldade de compreensão e qual o papel dos recursos didáticos na abordagem climatológica no processo de ensino-aprendizagem, tendo como objeto de estudo uma escola de Ensino Fundamental e Médio (Visconde do Rio Branco), localizada no município de Fortaleza - Ceará- Brasil.

\section{A climatologia no ensino da Geografia escolar na atualidade}

A Climatologia trata dos padrões de comportamento da atmosfera em suas interações com as atividades humanas e com a superfície terrestre no decorrer de um período de tempo muito longo (MENDONÇA et al, 2007). No ambiente do estudo geográfico a compreensão do clima está relacionada ao entendimento da nossa realidade social e histórica e, consequentemente, do ambiente em que vivemos. 
O clima é um dos elementos importantes nas questões cotidianas e, também, nas questões ambientais. Os processos atmosféricos influenciam nos demais mecanismos do ambiente, principalmente na biosfera, hidrosfera e litosfera. No entanto, não se podem ignorar os demais elementos do ambiente ao se estudar clima.

Partindo dos conhecimentos desses processos de análise e compreensão, podemos levar a sala de aula conceitos do clima com o objetivo de reconstruir com os alunos o seu entendimento de clima, assim como sua importância enquanto conteúdo da disciplina de Geografia. Para Ferretti (2009):

Ensinar Geografia, independentemente das diferenças entre os alunos, implica considerar o conjunto de conceitos-chave não como uma lista de conteúdos (entre estes, o clima) e, sim, como elementos norteadores das proposições curriculares, que por sua vez devem ser expostos de maneira interativa, em oposição a toda e qualquer visão individualizada e hierárquica do saber (p. 19).

A climatologia geográfica como conteúdo da disciplina de Geografia traz consigo diversas situações que podem ser abordadas dentro da sala de aula, assim como no ambiente escolar. Por exemplo, o quanto o clima interfere no modo de vestir das pessoas, permitindo assim, uma percepção da importância da abordagem climatológica para o entendimento da relação sociedadenatureza.

Atualmente o que se percebe são o desenvolvimento e aplicação de novas metodologias e abordagens de análise restritas ao ambiente acadêmico, não perpassando os espaços escolares. Parte disso se deve a confusão disciplinar do tema tratado no currículo escolar do Ensino Fundamental, uma vez que os estudos sobre o clima são atribuídos também à disciplina de ciências.

Diferentemente dos períodos anteriores, os PCN consagram a não mera constatação e descrição dos fenômenos que constituem a climatologia como conhecimento. Esse conjunto de documentos salienta que a grande valia pedagógica é explicar e compreender as interações entre a sociedade e natureza de modo processual situando-se em diferentes escalas espaciais e temporais, além de compará-las com significados através das contextualizações. Deve-se explorar o imaginário dos alunos para constituir com eles as mediações que permitam como objetivo maior a possibilidade de "[...] com os pés solidamente ligados aos seus lugares, aos poucos descobrirem o mundo e redimensionarem a experiência com o seu próprio lugar, isto é, redescobrirem seus próprios lugares e o mundo [...]" (BRASIL, 1998; 31-32).

O que se pretende no ensino fundamental segundo segmento com o ensino de climatologia é a compreensão de suas relações e interações na construção das paisagens, territórios, lugares, etc. Essa pretensão, também, visa à compreensão por parte do discente de que ele próprio é parte 
constituinte do ambiente como agente ativo e passivo nas transformações na organização do espaço geográfico.

Entretanto, entre as várias dificuldades encontradas pelo docente de Geografia, destacamos: a abordagem dos conteúdos da climatologia de acordo com as suas mais recentes concepções, diante dos recursos (in) disponíveis na maioria das escolas da rede pública de Ensino Fundamental e o esforço intelectual a ser feito para sua conotação geográfica específica de disciplina escolar.

Com isso, faz-se necessário discutir o que ensinar, para quê ensinar e como ensinar? Pensando assim, na importância do planejamento do professor no âmbito de procurar inserir na prática educativa o que de fato contribuirá com a formação dos sujeitos envolvidos no processo de ensino-aprendizagem.

\section{O processo, o ensino, o professor, o aluno e o estudo de clima}

O processo de ensino-aprendizagem em sala de aula exige cada vez mais a dedicação do professor para que o conteúdo ministrado seja repassado de forma dinâmica, eficiente e prazerosa. Assim, os professores assumem um papel de suma importância e a boa didática desenvolvida por esses profissionais é essencial.

A gestão da escola, também, tem um papel fundamental, pois com o apoio seja ele estrutural e/ou pedagógico da instituição, a forma como o docente e o aluno irão se relacionar também será afetada. Os mecanismos que estão relacionados com a didática devem ser entendidos para que a transmissão e/ou assimilação atinja seu objetivo de modo mais claro e coerente.

O processo de ensino é objeto da Didática, sendo definido como uma sequência de atividades do docente e dos discentes. Ele não é somente uma transmissão de informações, mas também o meio de organizar a atividade de estudo dos alunos. O ensino é uma atividade bastante complexa, pois envolve tanto condições externas como também, internas das situações didáticas.

O ensino obedece a uma direção e seu desdobramento tem um caráter intencional e sistemático, visando alcançar determinados resultados e possuindo um caráter bilateral. O professor tem a função de planejar e controlar o processo de ensino, tendo em vista estimular e suscitar a atividade própria dos alunos para a aprendizagem.

No estudo de clima, por exemplo, esses procedimentos são essenciais, devido à dificuldade de esclarecer ao aluno pontos importantes sobre o assunto e ainda associá-los a outros aspectos, sendo necessário criar ferramentas capazes de trazer para as salas de aula estratégias dinâmicas, levando os alunos a serem agente ativo no processo de ensino-aprendizagem, descobrindo novas possibilidades de análise, observando e compreendendo a dinâmica climática em suas variadas escalas. Com os avanços impostos à sociedade nas últimas décadas, os docentes vão sentindo a 
necessidade de ampliar e aplicar novas técnicas no processo didático para adequarem-se a essas exigências.

No ensino de Geografia, a climatologia apresenta uma importância fundamental, pois há uma interação bem presente da natureza-sociedade apresentadas no cotidiano dos alunos. Compreendendo essa dinâmica, o aluno é levado a perceber o clima e seus elementos, apesar de sua abstração, ao invés de simplesmente memorizar os conceitos relacionados à climatologia, que muitas vezes são tratados de forma desinteressada por parte dos alunos.

$\mathrm{Na}$ atualidade, temos a inserção cada vez mais de novos instrumentos no ambiente escolar com a inserção das novas tecnologias, interferindo de maneira informacional no processo de ensinoaprendizagem, proporcionando aos alunos elementos de distração, mas ao mesmo tempo de possibilidades na construção do conhecimento geográfico.

\section{METODOLOGIA}

A metodologia utilizada para a pesquisa seguiu as seguintes etapas:

- No primeiro momento foi realizada pesquisa bibliográfica sobre os temas abordados neste estudo, necessários às temáticas: Ensino de Geografia e abordagem climatológica; A utilização e importância dos recursos didáticos; pesquisa qualitativa em estudos de caso; dentre outros.

- Na segunda etapa realizamos a escolha da escola a ser trabalhada nesta pesquisa e fizemos os primeiros contatos com os responsáveis da escola: Diretor, coordenadores, professores de Geografia, funcionários e também os alunos.

- Na terceira etapa dialogamos junto ao professor (a) responsável pela disciplina de Geografia, com intuito de planejar como seriam realizadas as demais etapas da pesquisa.

- Na quarta etapa foram realizadas as observações em sala de aula, infraestrutura física da escola, espaços dedicados aos alunos, sala de multimeios (biblioteca, sala de vídeo, sala de informática), sala dos professores, secretaria, coordenação, diretoria, e dependências externas da escola.

- Na quinta etapa realizamos entrevistas com alunos e o professor (a) de Geografia responsável pelas turmas de sexto ano da escola.

- A sexta etapa consistiu em um trabalho laboratorial para verificar através de gráficos os dados obtidos quanto ao que foi levantado durante as entrevistas. 
- A sétima etapa aconteceu através da intervenção pedagógica feita em duas turmas de sexto ano da escola, com o objetivo de esclarecer dúvidas relacionadas ao conteúdo de climatologia, assim como, de construir junto aos alunos o recurso didático baseado no conteúdo que os mesmos têm maior dificuldade de assimilarem.

\section{RESULTADOS E DISCUSSÕES}

A partir de agora apresentaremos resultados coletados nas entrevistas através de gráficos, onde posteriormente serão analisados de acordo com as evidências e dados observados. Utilizamos a técnica de elementos da explanação de uma análise de evidências de um estudo de caso que: explica um fenômeno, estipula um conjunto de elos causais de "como" e "por que" algo aconteceu.

Gráfico 01: Questionamento um

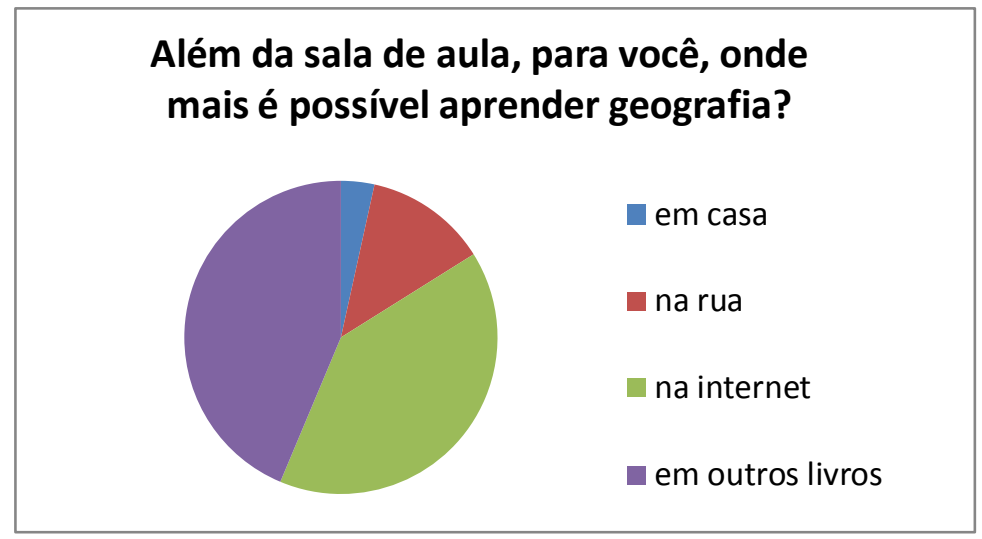

Com efeito ao que foi apresentado até o momento, procuramos saber até onde a Geografia está presente no dia-a-dia desses alunos, questionando-os sobre a possibilidade de se aprender geografia extra sala de aula.

Dos alunos entrevistados, 50\% disseram que também é possível aprender Geografia na Internet; $44 \%$ em outros livros; $4 \%$ na rua e $2 \%$ em suas residências. Isso demonstra a importância que o acesso às mídias digitais tem hoje na formação de muitos alunos. Na maioria dos números apresentados podemos verificar o papel da internet quanto ao acesso de conteúdos da ciência geográfica disponíveis.

Podemos perceber também a presença dos livros didáticos e paradidáticos na contribuição do aprendizado desses alunos. Através do acesso aos livros esses alunos afirmaram aprender Geografia. Pensando nesse questionamento, veio à importância atribuída às abordagens que os livros proporcionam, desde sua linguagem adequada até sua explanação sobre as questões apresentadas.

Uma evidência presenciada quanto a essa questão dos livros é a própria escola, E.E.F.M. Visconde do Rio Branco que incentiva à leitura, através de projetos que trabalham a importância 
dos livros na formação dos alunos. Nessa escola presenciamos um projeto intitulado "Este eu indico", com o objetivo de trazer o hábito da leitura aos alunos, seja na escola ou na sua própria residência.

Algo pouco abordado pelos alunos foi à possibilidade de aprender Geografia em casa ou no seu próprio convívio externo, e assim trazer conhecimento geográfico do seu próprio cotidiano.

Uma evidência observada durante as aulas de Geografia foi a não tentativa de trazer, por parte de incentivos do professor, a presença da comunidade escolar e do próprio percurso dos seus alunos ao ambiente de sala de aula; e assim fazer os alunos pensarem na Geografia como uma disciplina que poderá estar presente em diversos ambientes e que esses deverão ser trazidos para sala de aula na tentativa de associar esses conhecimentos prévios ao conhecimento científico.

Gráfico 02: Questionamento dois

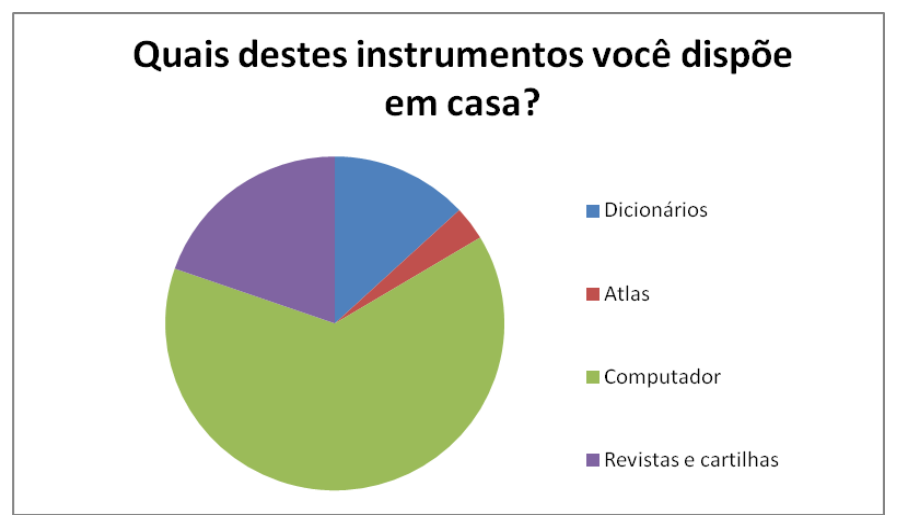

Mais uma vez podemos perceber a presença das mídias digitais no ambiente de vivências desses estudantes, onde dos 87 alunos entrevistados, 61 disseram ter esses instrumentos. 64\% possuem computadores em suas residências; $21 \%$ possuem revistas ou cartilhas educativas; $13 \%$ possuem dicionários e $2 \%$ atlas.

Cabe ressaltar que o computador toma cada vez mais tempo dos alunos, seja através de pesquisas ou de entretenimentos advindos da internet, assim cabe à escola e ao professor trazer essas mídias para a sala de aula e tentar mostrar a esses alunos que a informação está presente em diversos espaços e ambientes, mas a construção do conhecimento deverá ser feita em conjunto à presença do professor e dos demais alunos.

Essa percepção foi notada durante as aulas, onde muitos alunos comentaram sobre informações acessadas através dos computadores, sendo esse um momento de suma importância no auxilio da construção do conhecimento geográfico, tentando trazer a associação dessas informações com o conteúdo apresentado. Para KIMURA (2008):

A aprendizagem pode ser entendida comoo processo pelo qual o ser humano percebe, experimenta, elabora, incorpora, acumula as informações da realidade transformadas em 
conhecimento. O ser humano desenvolve esse processo em diferentes patamares através de um fazer em sua relação com o mundo (p. 46-47).

Mostra-se a partir desse pensamento a preocupação em fazer o aluno interiorizar e incorporar as informações, elaborando cumulativamente o acervo do seu universo sociocultural e do seu organismo natural.

Gráfico 03: Questionamento três

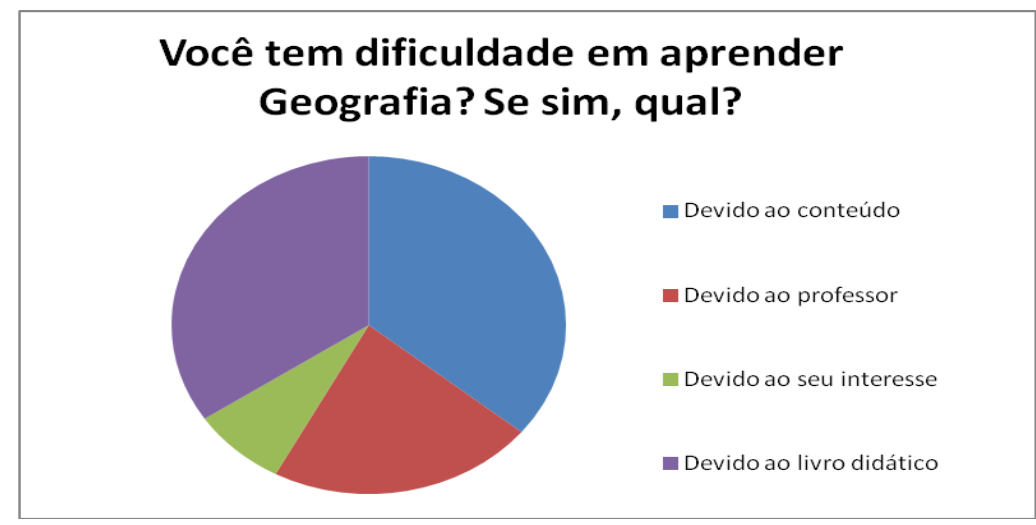

Dentre outras questões referentes ao ensino de Geografia pedimos que os alunos respondessem se há alguma dificuldade relacionada à aprendizagem da matéria de Geografia. Assim obtivemos as seguintes afirmações: dos 87 alunos entrevistados, 64 responderam que sim, têm alguma dificuldade em aprender Geografia, dos que responderam, 36\% afirmaram ser devido ao conteúdo abordado; $34 \%$ disseram que o motivo da dificuldade é pelo livro didático; $22 \%$ afirmam ser por causa do professor de Geografia e $8 \%$ dos entrevistados julgaram ser devido ao interesse próprio pela matéria.

Tentando agregar evidências a essas afirmações quantitativas, tentamos dar caráter qualitativo por meio das observações feitas e dos documentos analisados, pois quando esses alunos atrelam as dificuldades aos conteúdos e aos livros didáticos, sendo esses representando $70 \%$ dos entrevistados demonstra-se a fragilidade da abordagem geográfica dentro de sala de aula, ainda mais sendo contribuída com ausência do fazer pensar dos alunos nos livros didáticos. Para Kimura "O ser humano, sendo efetivamente um ser ativo, relaciona-se com o mundo exterior pela ação que articula o pensamento e a realidade exterior" (2008, p.46).

Quanto à relação devido ao professor e ao interesse dos alunos, podemos julgar a permanência das dificuldades de trazer uma Geografia, por parte dos professores e da própria escola, que represente o cotidiano daquele aluno ao invés de transformar o conteúdo geográfico em mera descrição, contribuindo assim para que os alunos a encarem como uma matéria enfadonha e decorativa. 
Gráfico 04: Questionamento quatro

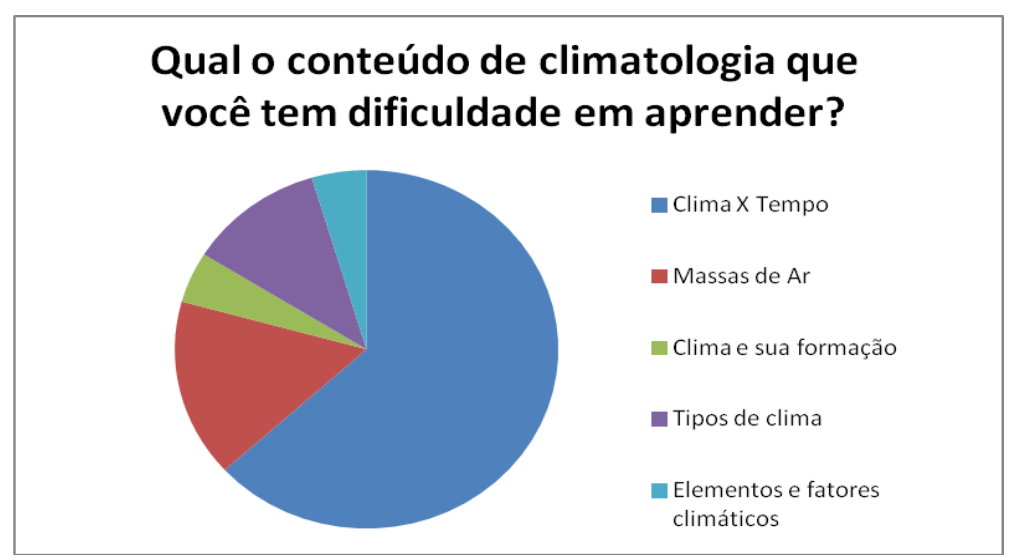

Podemos perceber que até o momento estamos discutindo de modo a respeitar a prática educativa em Geografia, onde foram realizados questionamentos referentes aos alunos envolvidos no processo de ensino-aprendizagem, a opinião desse sujeito quanto ao conteúdo da ciência geográfica, quanto ao papel do professor em sala de aula, às dificuldades encontradas no aprender Geografia, aos recursos disponíveis como instrumentos que contribuirão com a aprendizagem.

A partir dessas explanações realizadas sobre a prática em Geografia, iniciamos um questionamento direto à abordagem climatológica, tentando verificar as relações observadas anteriormente com as dificuldades dos alunos em aprender os conteúdos de climatologia. Dos 87 entrevistados, $63 \%$ dos alunos (equivalente a 55 alunos) afirmaram ter maior dificuldade em definir e diferenciar TEMPO X CLIMA; já 16\% dos entrevistados (equivalente a 14 alunos) disseram ter maior dificuldade em aprender conteúdos sobre MASSAS DE AR; 11\% (equivalente a 11 alunos) afirmaram ter dificuldade em entender os TIPOS DE CLIMA; 5\% (equivalente a 4 alunos) julgaram ter maior dificuldade em assimilar CLIMA E SUA FORMAÇÃO e 5\% (equivalente a 4 alunos) afirmaram dificuldades de aprender ELEMENTOS E FATORES CLIMÁTICOS.

Para melhor expressar o que foi observado, cabem aqui algumas definições e diferenciações de Clima e Tempo, segundo alguns autores da área de estudo. Como segue no quadro abaixo:

\begin{tabular}{|c|c|}
\hline TEMPO & CLIMA \\
\hline $\begin{array}{l}\text { Tempo é o "conjunto de valores que, em um dado } \\
\text { momento e em um determinado lugar, caracterizam o estado } \\
\text { atmosférico" (PÉDELABORDE, 1970). }\end{array}$ & $\begin{array}{l}\text { Hann (1882): "Clima é o conjunto de elementos } \\
\text { meteorológicos que caracterizam o estado médio da atmosfera } \\
\text { num determinado ponto sobre a superfície terrestre". }\end{array}$ \\
\hline $\begin{array}{l}\text { Tempo atmosférico ou meteorológico: é o estado } \\
\text { atual da atmosfera em determinado local e instante, sendo } \\
\text { caracterizado pelas condições de temperatura, umidade, }\end{array}$ & $\begin{array}{l}\text { Sorre (1934): "Clima passa a ser o ambiente } \\
\text { atmosférico constituído pela série de estados da atmosfera em } \\
\text { um determinado lugar e sua sucessão habitual". }\end{array}$ \\
\hline
\end{tabular}


vento, radiação, chuva, etc (AYOADE, 2004).

Tempo é o estado da atmosfera num determinado momento, que pode ser interpretado sob as escalas convencionais que podem considerar a atmosfera como quente ou fria, úmida ou seca (JACOBSON, 2005).
OMM (1960): estado médio da atmosfera caracterizado pela temperatura, umidade, vento, chuva, pressão, radiação solar etc, em um período de no mínimo trinta anos (30) de observação.

\section{Quadro 01: Definições de Tempo e Clima}

Durante as observações em sala de aula foi possível perceber algumas dificuldades relacionadas ao conteúdo de climatologia. Tive a oportunidade de acompanhar as turmas do sexto ano nos dias em que o professor ministrou os assuntos da climatologia para tentar verificar através da prática como esse conteúdo está sendo abordado dentro da sala de aula.

Foram reservadas seis aulas, distribuídas em três semanas para abordar o conteúdo de climatologia pelo professor. De início percebemos novamente o protagonismo do livro didático em sala de aula, portanto, um dos fatores que mais motivou esta pesquisa na possibilidade de utilização de outros auxílios no processo de ensino-aprendizagem.

Dentre eles poderiam ser listados o próprio globo, livros paradidáticos existentes na biblioteca da escola, mapas de diferenciações climáticas, cartilhas, jornais, revistas, vídeos, internet, software etc. Esses recursos a todo o momento trazem contribuições sobre a dinâmica climática mundial, nacional, regional e local, e assim podem contribuir com o aprendizado dos alunos.

Fazendo uma relação ao que foi encontrado nas entrevistas, e principalmente, na indagação sobre as dificuldades quanto ao conteúdo de climatologia, podemos trazer evidências da pesquisa para tentar solucionar tais deficiências. Uma delas é a própria dificuldade do professor responsável pelas turmas de abordar o tema em sala de aula.

O professor responsável pela disciplina nessa escola tem formação de licenciatura em História, esse fato não é o bastante para afirmar tais dificuldades, mais se um profissional de uma área de formação diferenciada de um professor de Geografia não tem embasamento teórico sobre a ciência geográfica e ainda, não buscar meios de agregar aprendizagem à sua prática educativa em sala de aula, isso contribuirá para permanecer com tais deficiências.

Vivemos em uma realidade bem diferente da que imaginamos dentro de uma estrutura educacional pública, com déficits de estrutura física e pedagógica, problemas com gestores escolares, deficiência no quadro de professores qualificados para suprir as necessidades da escola e etc. Isso demonstra a necessidade de locar um professor de outra disciplina na que necessita de locação urgente. Durante as aulas que foram abordadas os conteúdos de climatologia, percebemos a grande dificuldade de desprendimento do livro didático por parte do professor, trazendo essa 
evidência para o que confirmado pelo próprio professor após a aula quando disse: "Não tenho nenhuma afinidade em trabalhar com esses aspectos físicos".

Seguindo a lógica de tais deficiências passamos a observar os alunos. Quando partimos para as entrevistas, os alunos não pareciam tão preocupados com a situação vivenciada em sala de aula, embora alguns sempre voltavam ao professor para mais aprofundamento e exemplificações das diferenciações dos conteúdos de climatologia.

Ao iniciar as entrevistas, explicamos os objetivos, foi notado o interesse deles em contribuir com a pesquisa. Durante os questionamentos os alunos refletiram sobre o aprendizado naquele tema, fator que na maioria das vezes não é trabalhado dentro de sala de aula, onde o que importa é repassar o conteúdo sem entender em quais aspectos o assunto abordado irá contribuir para a formação do aluno.

Quando esboçamos em gráficos os dados, associamos as evidências registradas na prática educativa junto com o resultado das dificuldades. Em um determinado momento da aula, quando o professor iniciou a abordagem do tema com as definições de tempo e clima, percebemos que os únicos conceitos e definições que o professor tinha para repassar aos alunos eram aqueles que estavam no livro didático.

Posteriormente, os alunos começaram a refletir sobre essas definições e tentaram perceber através de associações, exemplificações e nisso o professor não pode contribuir. A todo o momento ele voltava a aula para o livro didático, sendo que este, deixa grandes lacunas quanto ao conteúdo de climatologia e a forma como são apresentados no livro.

Em nenhum momento da aula o professor perguntou o que seria tempo e clima para aqueles alunos ou trouxe para a realidade daqueles alunos os conceitos para contribuir no entendimento climático, não houve associações e exemplificações práticas e próximas da linguagem daqueles alunos.

Uma das propostas eficazes no aprendizado dos alunos quanto a Geografia Física, além de exemplificações e associações, é a utilização de recursos didáticos em sala de aula. Visto a abstração de muitos conteúdos da Geografia física e da carência de metodologias que trabalhem de forma simples esses assuntos.

Como visto, nos resultados das entrevistas, $67 \%$ dos alunos disseram ter maior dificuldade em definir e diferenciar tempo e clima, contudo para qualificar essa pesquisa questionamos o porquê de tempo e clima. Obtivemos diversas respostas, entre elas:

- "Eu não consigo diferenciar isso tudo da matéria de História" ( $6^{\circ}$ ano A);

- Tempo pra mim é da hora e clima pra mim é o de hoje, que está quente" ( $6^{\circ}$ ano $\left.\mathrm{A}\right)$;

- "Professor porque tenho que aprender isso mesmo?" (6 $6^{\circ}$ ano A); 
- "Eu não consigo perceber o tempo, mas consigo perceber o clima" (6 $6^{\circ}$ ano $\left.\mathrm{A}\right)$;

- "Muito difícil isso, pra mim tudo é a mesma coisa" ( $6^{\circ}$ ano B);

- Não sei, mas acho que deve ser porque meu professor não sabe ensinar" ( $6^{\circ}$ ano B).

Visto essas questões levantadas pelos alunos percebemos, ainda, a ausência da relevância em trazer os conceitos, definições, e percepções desses alunos para o ambiente escolar, não sendo a solução dos problemas, mas uma alternativa no aprendizado desses alunos incentivá-los a perceberem a necessidade de entenderem conceitos e definições, tendo importância nos conhecimentos prévios e relacionando-os ao conhecimento científico.

Destacamos a necessidade de se atentar às possibilidades de abordagem dos conhecimentos, propondo o recurso didático como um importante meio ao aprendizado desses alunos. Pois "o material a ser utilizado deve proporcionar ao aluno o estímulo à pesquisa e a busca de novos conhecimentos, o propósito do uso de materiais concretos no ensino escolar é o de fazer o aluno a adquirir a cultura investigativa" (KAERCHER, op cit).

\section{REFERÊNCIAS}

AYOADE, J. O. Introdução a Climatologia para os Trópicos, 9a edição, Rio de Janeiro: Bertrand, 2004.

BRASIL. Ministério da Educação. Secretaria de Educação Média e Tecnológica. Parâmetros Curriculares Nacionais ( $5^{\mathrm{a}}$ a $8^{\mathrm{a}}$ série),Brasília, MEC, 1998. p 55- 62

BRASIL. MEC. Lei de Diretrizes e Bases da Educação. Disponível em: 〈http://www.mec.gov.br>. Acesso em: 10 fevereiro 2012.

GIL, Antonio Carlos. Métodos e técnicas de pesquisa social / Antonio Carlos Gil. - 6. ed. - 3. reimpre. - São Paulo: Atlas, 2010.

GLASER, B.; STRAUSS, A. The discovery of grounded theory. New York: Aldene de Gruyter, 1967. 271p.

HANN, J.F. (1882): Handbuch der Klirnatologie. Wien, 764 pp.

KAERCHER, N. A. Desafios e utopias no ensino de Geografia. São Francisco do Sul - RS:

Edunisc, 2003.

KIMURA, Shoko. Geografia no Ensino Básico. São Paulo, Editora Contexto, 2008.

MENDONÇA, Francisco, OLIVERIA, Inês Moresco Danni. Climatologia- Noções básicas e climas do Brasil. São Paulo: Oficina de Textos, 2007, p. 11-25.

PÉDELABORDE, P. Introduction à l'étude scientifique du climat. Paris: SEDES, 1970. 246 p. PROJETO ARARIBÁ: Geografia, $5^{\text {a }}$ série. Obra coletiva, $1^{\text {a }}$ edição, Moderna, São Paulo, 2006, p 
SILVA, E. I. A linguagem dos quadrinhos na mediação do ensino de Geografia: charges e tiras de quadrinhos no estudo de cidade, 2010. Tese (Doutorado em Geografia) - Instituto de Estudos Socioambiemtais - Universidade Federal de Goiás, Goiânia, 2010.

SORRE, M. Le Climat. In: SORRE, M. Les Fondements de la Géographie Humaine. Paris: Armand Colin, 1951. Chap. 5, p.13-43.

SOUZA, Salete Eduardo de. O uso de recursos didáticos no ensino escolar. In: I Encontro de Pesquisa em Educação, IV Jornada de Prática de Ensino, XIII Semana de Pedagogia da UEM: "Infância e Práticas Educativas". Arq Mudi. 2007. Disponível em: http://www.pec.uem.br/pec_uem/revistas/arqmudi/volume_11/suplemento_02/artigos/019.pdf Acesso em: 05 de abril de 2008.

VESENTINI, José Wuillian, Geografia e ensino: Textos críticos, Tradução: Josetti Gian, $9^{a}$ edição, Campinas-SP, Papirus, 2006, p.161-179

Yin Robert K. Estudo de caso : planejamento e métodos / Robert K. Yin : tradução Ana Thorell ; revisão técnica Cláudio Damacena. - 4. Ed. - Porto Alegre : Bookman, 2010. 248 p.

Recebido em: 14/08/2016

Aceito para publicação em: 01/10/2016 